\title{
Chick Embryo: A Preclinical Model for Understanding Ischemia-Reperfusion Mechanism
}

\author{
Eram Fauzia', Tarun Kumar Barbhuyan ${ }^{1}$, Amit Kumar Shrivastava', Manish Kumar', \\ Paarth Garg ${ }^{1}$, Mohsin Ali Khan ${ }^{2}$, Avril A. B. Robertson ${ }^{3}$ and Syed Shadab Raza ${ }^{1,4 *}$ \\ ${ }^{1}$ Laboratory for Stem Cell and Restorative Neurology, Department of Biotechnology, Era's Lucknow Medical College \\ and Hospital, Era University, Lucknow, India, ${ }^{2}$ Era's Lucknow Medical College and Hospital, Era University, Lucknow, India, \\ ${ }^{3}$ School of Chemistry and Molecular Biosciences, The University of Queensland, Brisbane, QLD, Australia, ${ }^{4}$ Department of \\ Stem Cell Biology and Regenerative Medicine, Era University, Lucknow, India
}

Ischemia-reperfusion (I/R)-related disorders, such as stroke, myocardial infarction, and peripheral vascular disease, are among the most frequent causes of disease and death. Tissue injury or death may result from the initial ischemic insult, primarily determined by the magnitude and duration of the interruption in blood supply and then by the subsequent reperfusion-induced damage. Various in vitro and in vivo models are currently available to study I/R mechanism in the brain and other tissues. However, thus far, no in ovo I/R model has been reported for understanding the $\mathrm{I} / \mathrm{R}$ mechanisms and for faster drug screening. Here, we developed an in ovo Hook model of I/R by occluding and releasing the right vitelline artery of a chick embryo at $72 \mathrm{~h}$ of development. To validate the model and elucidate various underlying survival and death mechanisms, we employed imaging (Doppler blood flow imaging), biochemical, and blotting techniques and evaluated the cell death mechanism: autophagy and inflammation caused by I/R. In conclusion, the present model is useful in parallel with established in vitro and in vivo $\mathrm{I} / \mathrm{R}$ models to understand the mechanisms of $\mathrm{I} / \mathrm{R}$ development and its treatment.

Keywords: ischemia-reperfusion, chick embryo, Hook I/R model, Doppler blood flow imaging, autophagy, NLRP3 inflammasome, MCc950

drshadab@erauniversity.in, syedshadabraza@gmail.com

Specialty section:

This article was submitted to Experimental Pharmacology and Drug Discovery,

a section of the journal

Frontiers in Pharmacology

Received: 04 June 2018

Accepted: 27 August 2018 Published: 21 September 2018

Citation:

Fauzia E, Barbhuyan TK, Shrivastava AK, Kumar M, Garg P, Khan MA, Robertson AAB and Raza SS (2018) Chick Embryo:

A Preclinical Model for Understanding Ischemia-Reperfusion Mechanism.

Front. Pharmacol. 9:1034. doi: 10.3389/fphar.2018.01034

\section{INTRODUCTION}

The incidence of ischemia-reperfusion (I/R) injury is high, and its pathogenesis involves complex, multifactorial, and interrelated processes. I/R contributes to the pathophysiology of stroke, myocardial infarction, peripheral vascular insufficiency, and other thrombotic events. Prolonged ischemia results in detrimental cellular metabolic and ultrastructural changes. Thus, to minimize or prevent irreversible cellular injury, restoring blood supply is essential. Notably, reperfusion can augment the tissue injury compared with that produced by ischemia alone (Mathes et al., 2016; Tejada et al., 2016; Silachev et al., 2017). Thus, prompt revascularization and blood flow restoration, with minimal damage to the reperfused area, remain the mainstay of all current therapeutic approaches for I/R (Linfante and Cipolla, 2016; Strand-Amundsen et al., 2018; Xiong et al., 2018; Yan et al., 2018). To mimic the aforementioned mechanism, suitable models closely resembling human pathology in clinical conditions are needed, that can contribute to our understanding of the mechanisms underlying I/R injury (Milcan et al., 2004; Lai et al., 2006; Kalogeris et al., 2012, 2016; Horvath et al., 2016; Ross et al., 2016; McBride and Zhang, 2017). Such models aid the understanding of $\mathrm{I} / \mathrm{R}$ mechanisms and are also used in drug testing pipelines; ultimately translating to improved patient care. 
In the last three decades, several critical factors that can act in concert to mediate the detrimental effect of I/R injury have been identified. However, till date no treatment directed to I/R injury has shown to lead to an improvement in clinical outcomes. This is primarily because of the lack of our complete understanding of the complexity of disease progression, and secondarily because of inappropriate research model selection. Currently, multiple species, including non-human primates, rodents, felines, and certain avian species, are used in $\mathrm{I} / \mathrm{R}$ research. The disparity between the results obtained using these models and the results of clinical trials, in humans, have led to the development of newer experimental model (Allen et al., 2005; Schmeer et al., 2008; Anvret et al., 2012; Xu et al., 2014; Gonzalez et al., 2015; Huang et al., 2016; Sommer, 2017; Yang et al., 2018). In this study, we used chick embryos as an alternative model to study the underlying mechanism of I/R injury.

Unborn embryos, such as chick, zebrafish, and Xenopus, have been extensively used in biomedical research. Chick embryos are widely used because of their ready accessibility, ethical acceptability, relatively large size, cost effectiveness, and fast growth (Seabra and Bhogal, 2010). Chick embryos have played a vital role in anatomical, embryological, developmental biology studies and they are an effective model for blood circulation research (Harvey, 1628; Lee et al., 2011; Smith et al., 2016). Furthermore, the blood vessel network of chick embryos can be a repository system for implanted human cells without any rejection (Wilson and Chambers, 2004; Deryugina and Quigley, 2009). Because the third day chick embryos possess a well-defined circulatory system, we selected a 72-h chick embryo as an appropriate model to study the $\mathrm{I} / \mathrm{R}$ mechanism (Figure 1A). The model used (hereafter referred to as the Hook I/R model) in the present study can effectively mimic all downstream pathway, e.g., oxidative and inflammatory pathways. Our model is simple, reproducible, and can be used for drug screening, and for routine I/R studies.

\section{MATERIALS AND METHODS}

\section{Ethics Statement}

The experimental protocol for the use of chick embryos was submitted to the Era's Lucknow Medical College and Hospital's Institutional Animal Ethical Committee, which issued a written waiver stating that according to the Committee for the Purpose of Control and Supervision of Experiments on Animal (CPCSEA) no formal approval was necessary to perform these experiments. Though, Standard Operating Procedures were followed to minimize any possible suffering by embryos.

\section{Materials and Equipment}

We used fertilized White Leghorn chicken eggs, $37^{\circ} \mathrm{C}$ egg incubator (Lab Guard, India), Kim-wipe, 70\% ethanol, surgical scissors, 26G needle and syringe, laser Doppler blood flow imaging system (Moors Instrument, United Kingdom), micromanipulator (Narishige, United States), and surgical microscope (Olympus, Japan). The primary antibodies used were rabbit polyclonal anti-HIF1 $\alpha$ (NB100-449, Novus Biologicals), mouse polyclonal anti-LC3 (SC16756, Santa Cruz), rabbit polyclonal anti-Beclin1 (24352, SAB), rabbit polyclonal antiSOD 1 (3458-100, Biovision), rabbit polyclonal anti-SOD 2 (NB100-1992SS, Novus Biologicals), rabbit monoclonal Caspase-1 (ab179515, Abcam), mouse monoclonal Caspae3 (NB100-56708SS, Novus Biologicals), mouse monoclonal Cathepsin B (ab58802, Abcam), rat monoclonal LAMP1 (ab25245, Abcam), mouse monoclonal LAMP-2 (NBP2-22217SS, Novus Biologicals), rabbit monoclonal IFN $\gamma$ (ab133566), rat monoclonal anti-NLRP3 (MAB7578-SP, Novus Biologicals), rabbit polyclonal anti-ASC (PA5-50915, Invitrogen), mouse monoclonal anti-IL-1 $\beta$ (701304, Invitrogen), rabbit polyclonal anti-Ambra 1 (GTX17003, Genetex), rabbit polyclonal antiATG7 (PA535203, Themofisher), rabbit polyclonal anti-SQSTM1 (PA520839, Invitrogen), rabbit polyclonal anti-ORP150 (NBP214113, Novus Biologicals), rabbit polyclonal anti-NF-K $\beta$ (51-0500, Invitrogen), rabbit polyclonal anti-TNF $\alpha$ (NB600587SS, Novus Biologicals), and rabbit polyclonal anti-GAPDH (ITI5052, GBIO). The secondary antibodies were HRPconjugated donkey anti-rabbit (Jackson ImmunoResearch, 126333) and HRP-conjugated goat anti-mouse (Cell Signaling Technology, 70765) antibodies. An ECL chemiluminescence kit (Biorad, 170-5060), RIPA (Sigma Aldrich, R0278), protease inhibitor (Cell Signaling Technology, 5872), 2-thiobarbituric acid (Sigma Aldrich, T5500), sulfanilamide (Sigma Aldrich, S9251), and N-1-napthylenediamine (Sigma Aldrich, N9125) were obtained from the indicated sources.

\section{Chick Eggs and Embryos}

Fertilized White Leghorn chicken were procured from Central Avian Research Institute, Bareilly, Uttar Pradesh, India, and where kept in our in campus poultry farm. Zero-day-old eggs were incubated in a $37^{\circ} \mathrm{C}$ egg incubator at $60-65 \%$ humidity for $72 \mathrm{~h}$. After $24 \mathrm{~h}$, the eggs were taken out for layering: 5-6 mL of albumin was drawn out. On the third day of incubation, the eggs were removed from the incubator, and windowing was performed to assess the embryo as described below.

\section{Inducing Ischemia in the Chick Embryo Through the Hook I/R Method}

Ischemia was induced in the chick embryo at $72 \mathrm{~h}$ of development. The RVA, the artery responsible for carrying oxygen and nutrients to the embryo, was pulled out by a spinal needle [Ramsons, India; 25GA, $3.50 \mathrm{IN}(90.51 \times 90 \mathrm{~mm})$ ] under the guidance of a surgical microscope (Figure 1 and Supplementary Figure S1). Two small holes were created on the right and left side of the RVA in the sac (Supplementary Figure S2), with the help of $18 \mathrm{G}$ needle. A hook was customdesigned at the base of the spinal needle (Figure 1B), attached to the micromanipulator (Narishige, Japan) to lift up the RVA. The length of the bent part was approximately $1 \pm 0.5 \mathrm{~mm}$. The needle was inserted beneath the RVA through the two small holes created, to lift up the artery. The artery was raised gently till the Doppler reading for arterial blood flow showed a decreased of $80-90 \%$ of the baseline value. The Doppler was positioned 


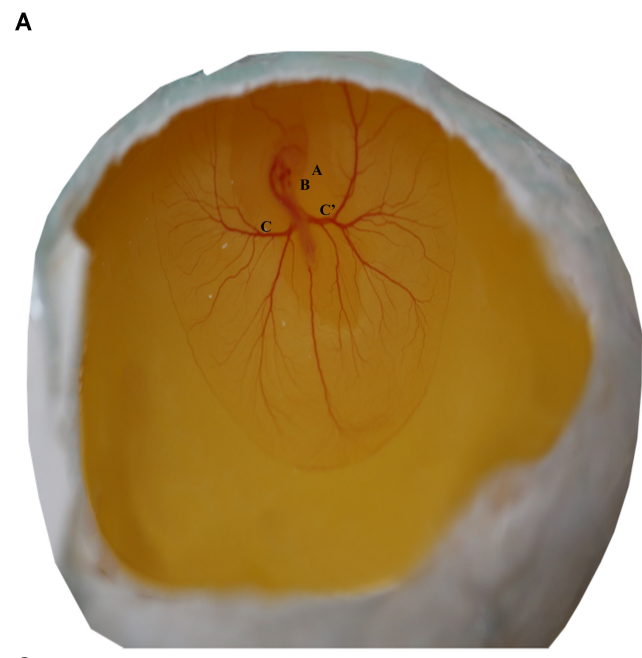

C
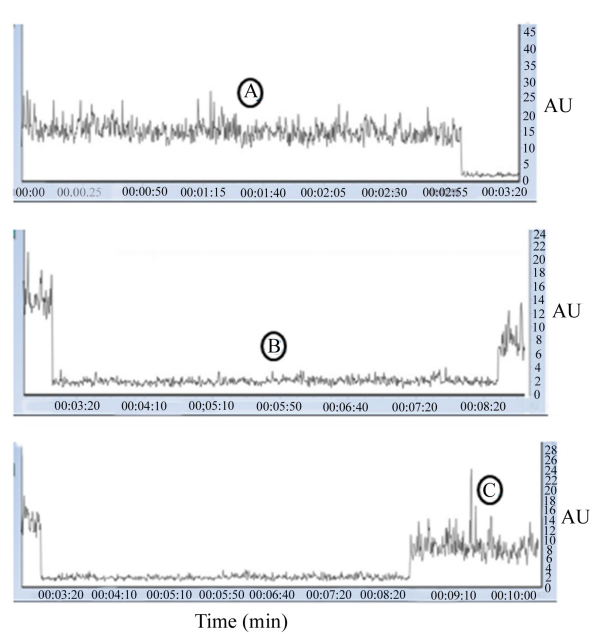

B

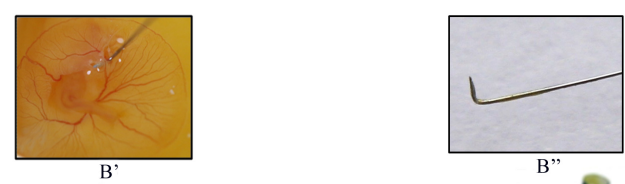

$D$
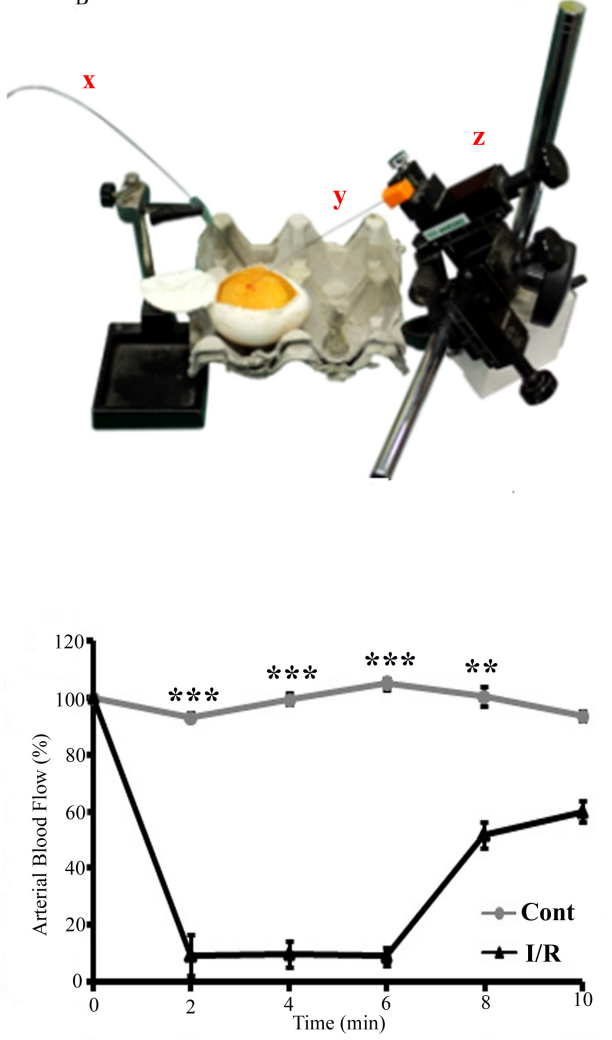

FIGURE 1 | Representative pictures of the I/R setup for Hook Model. (A) A 72-h Leghorn chick embryo in an in ovo culture, Annotations: $\mathrm{A}=$ eye, $\mathrm{B}=$ heart, $\mathrm{C}=$ left vitelline artery, C' = right vitelline artery. The rectangle area represents the site of the occlusion. (B) The typical setup to induce l/R, $\mathrm{x}=\mathrm{laser}$ Doppler flow probe, $y=$ spinal needle (insight picture shows the bent edge of the spinal needle), $z=$ micromanipulator. The magnification $\mathbf{B}$ ' shows the enlarge picture of the artery while occlusion. B" shows the spinal hook (arrow) inserted beneath RVA (arrow-head) to lift up the artery. (C) The changes in the flux during normoxia (A), ischemia (B), and reperfusion (C). (D) The baseline arterial blood flow in I/R treated RVA vs. control RVA, and the changes observed in I/R RVA during ischemia-reperfusion ( $n=12$ /group/experiments). Control represents Sham. ${ }^{* *} P<0.01$ and ${ }^{* * *} P<0.001$.

directly onto the RVA at a distance of $5 \pm 1 \mathrm{~mm}$ post-ischemic site (Supplementary Figure S2). Post-ischemia the artery was released slowly and the spinal needle was retracted back with the help of the micromanipulator. During reperfusion, the Doppler reading reached a normal value (Supplementary Figure S3). After $5 \mathrm{~min}$ of ischemia, reperfusion was allowed for the next $5.5 \mathrm{~h}$. After occlusion, a few drops of phosphate buffer saline were added to the yolk to prevent drying; subsequently, the egg was sealed with cello-tape and placed back into the $37^{\circ} \mathrm{C}$ incubator. After $5.5 \mathrm{~h}$, the egg was taken out of the incubator for further treatment. For the control experiments, Sham without surgery was taken.

\section{Vascular Blood Flow Imaging}

To validate the model, the blood flow in the RVA was monitored before, during, and after ischemia by using a laser Doppler flow meter (moorVMS-LDF1, Moor Instruments, United Kingdom; Figure 1C).

\section{Biochemical Analysis NO Estimation}

NO production was evaluated by measuring the level of nitrite (an indicator of NO) in the supernatant of right vitelline artery of control and experimental ischemic chick embryos using Griess reagent (Green et al., 1982). Briefly, $150 \mu \mathrm{L}$ of tissue supernatant was mixed with $150 \mu \mathrm{L}$ of Griess reagent [0.1\% $N$-(1-naphthyl) ethylene diamine dihydrochloride, $1 \%$ sulfanilamide, and 2.5\% $\left.\mathrm{H}_{3} \mathrm{PO}_{4}\right]$. After incubation at room temperature in the dark for $10 \mathrm{~min}$, absorbance was measured on a microplate ELISA reader (Biorad, United States) at $540 \mathrm{~nm}$. 

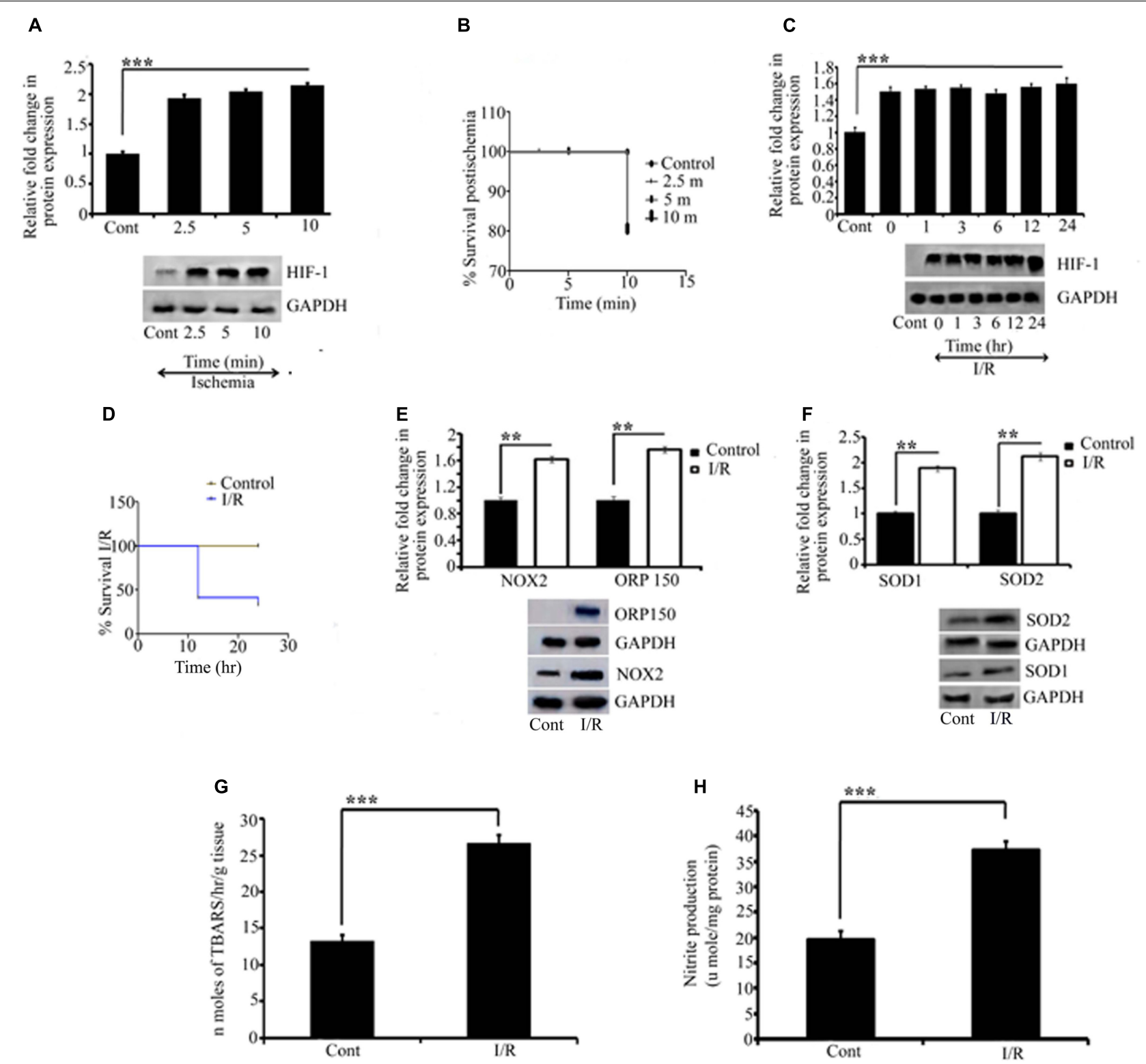

FIGURE 2 | Representative pictures of Effect of I/R on ischemic and oxidative parameters. Effect of I/R and the activation of oxidative stress were measured by quantifying HIF1 $\alpha$, NOX2, ORP150, SOD1, and SOD2 expression. Initially to measure the effect of ischemia, HIF1 $\alpha$ was quantified for different time point for which RVA was occluded (A). All the occlusion time point showed significant differences compared to control (***P<0.001). (B) The Kaplan Meier survival curve for the embryos receiving ischemia at different time points compared to the control ( ${ }^{*} P<0.05 ; n=12 /$ group/experiment). The effect of reperfusion was further quantified by $\mathrm{HIF} 1 \alpha$. A significant change as compared to the control was observed in all the time point since reperfusion is allowed $(* * * P<0.001)$. No significant differences were observed in-between the ischemia and reperfusion time points (C). Kaplan Meier survival curve for the reperfusion for different time points compared to the control showed a significant difference between ( $P<0.05 ; n=12$ /group/experiment) (D). (E,F) The changes in NOX2 (** $P<0.01)$, ORP150 (** $P<0.01)$, SOD1 $(* * P<0.01)$, and SOD2 (**P<0.01) compared to their respective controls. Results represent mean \pm SE $(n=3)$. The graph shows the densitometry quantification of western blot bands. (G) The changes in the level of TBARS after $6 \mathrm{~h}$ of I/R. Right, I/R vessels showed significant changes as compared to the right control $\left({ }^{* * *} P<0.001\right)$. No changes were observed in left control vitelline arteries vs. right control. (H) The changes in NO production in right I/R vs. right control vessels $\left({ }^{* * *} P<0.001\right)$. Results represent mean $\pm \mathrm{SE}(n=3)$. Control represents Sham in all the experiments. ${ }^{*} P<0.05$, ${ }^{* *} P<0.01$, and ${ }^{* * *} P<0.001$.

\section{Thiobarbituric Acid Reactive Substances Assay}

LPO was estimated by measuring thiobarbituric acid reactive substances (TBARS, a marker for LPO) following the method of Utley et al. (1967), with some modification. In brief, $0.2 \mathrm{~mL}$ of supernatant was pipetted into a $2.0 \mathrm{~mL}$ flat bottom eppendorf tube and was incubated at $37^{\circ} \mathrm{C}$ in a metabolic water bath shaker at 120 strokes up and down; another $0.2 \mathrm{~mL}$ of the same supernatant was pipetted into a microcentrifuge tube and was incubated at $0^{\circ} \mathrm{C}$. After $1 \mathrm{~h}$ of incubation, $0.4 \mathrm{~mL}$ of $5 \%$ TCA and $0.4 \mathrm{~mL}$ of $0.67 \%$ TBA were added to both samples 
(i.e., those incubated at 0 and $37^{\circ} \mathrm{C}$ ). The reaction mixture was centrifuged at $3000 \mathrm{~g}$ for $15 \mathrm{~min}$. The supernatant was transferred to another test tube and placed in a boiling water bath for $10 \mathrm{~min}$. Thereafter, the test tubes were cooled, and absorbance was read at $535 \mathrm{~nm}$. The LPO concentration is expressed as nmol of TBARS formed/h/mg protein using the molar extinction coefficient of $1.56 \times 10^{5} / \mathrm{M} / \mathrm{cm}$.

\section{Western Blotting}

The proteins (30 $\mu \mathrm{g}$; loaded to each well) from the RVA and its adjoining tissue (Supplementary Figure S2), from the control and I/R groups were analyzed through western blotting. In brief, tissues were lyzed in ice-cold RIPA buffer (Sigma Aldrich, R0278) containing protease and phosphatase inhibitors (Cell Signaling Technology, 5871S) and were homogenized in tissue homogenizer in the same buffer used for cell lysis and centrifuged at $20,000 \mathrm{~g}$ for $20 \mathrm{~min}$ at $4^{\circ} \mathrm{C}$. The protein concentration was measured using a Pierce BCA protein assay kit (Life Technologies, 23225). The proteins were then fractionated through SDS-PAGE and transferred on to a PVDF membrane (Biorad, 1610177). The membranes were blocked with 5\% nonfat milk, probed with primary antibodies overnight at $4^{\circ} \mathrm{C}$, and incubated with HRP-conjugated secondary antibodies at room temperature for $1 \mathrm{~h}$. Immunoblot bands were quantified using densitometry on ImageJ. Densities were normalized to control treatment, and relative fold changes were normalized to GAPDH.

\section{DNA Gel Electrophoresis for DNA Damage}

The I/R and control samples RVA (20 mg) were ground with liquid nitrogen, and DNA extraction buffer $(\mathrm{pH}$ 7.5) and proteinase $\mathrm{K}$ were added. The samples were then incubated in a heat block at $60^{\circ} \mathrm{C}$ for $30 \mathrm{~min}$ and centrifuged at $13,000 \mathrm{rpm}$ for $15 \mathrm{~min}$. Ammonium acetate $(5 \mathrm{M})$ and isopropanol were added to the supernatant, which was again centrifuged at the same speed $(13,000 \mathrm{rpm})$ for $5 \mathrm{~min}$. The DNA pellet was then washed with ethanol and re-suspended in $50 \mu \mathrm{L}$ of TE buffer containing RNAase for the experiment. The isolated DNA $(2 \mu \mathrm{g})$ from each treatment was examined for DNA damage by conducting DNA electrophoresis in $0.2 \%$ agarose gel in Tris/acetate buffer at $15 \mathrm{~V}$ for $2 \mathrm{~h}$. At the end of electrophoresis, DNA was visualized in Chemidoc (Las500, GE).

\section{Drug Treatment}

For drug treatment, the RVA was excised after $1 \mathrm{~h}$ of $\mathrm{I} / \mathrm{R}$, placed in Ringer's solution $\left(\mathrm{NaCl}, \mathrm{KCl}, \mathrm{CaCl}_{2}, \mathrm{pH}=7.4\right)$ containing antiischemic molecules [MD (Sigma Aldrich, M5199) and TMZ (i.e., 1-(2,3,4-trimethoxy benzyl); Sigma Aldrich, 653322)]; an antiinflammatory molecule (MCC950), a ROS inhibitor (NAC; Sigma Aldrich, A7250), and their respective controls and incubated at $37^{\circ} \mathrm{C}$ for another $4.5 \mathrm{~h}$.

\section{Statistical Analysis}

The results were statistically evaluated with different tests. All the experimentations have been done three times as $n=3$ /group/experiments, unless otherwise indicated. Significant differences between the experimental groups were analyzed with student's t test and with one-way ANOVA followed by NewmanKeuls multiple comparison test. Differences were considered statistically significant when $p<0.05$. All data were presented as means \pm SE. Student's $t$-test was used to analyze data presented in Figures 1D, 2E-H, 3B-F and Supplementary Figures S4, S5. One-way ANOVA followed by NewmanKeuls multiple comparison test was used to analyze data in Figures 1A,C, 4. Graph Pad Prism 5 software was used to calculate all the above data.

\section{RESULTS}

\section{Chick Embryo Hook I/R Model}

Ischemia-reperfusion was induced in a chick embryo by occluding the right vitelline artery (RVA) for $5 \mathrm{~min}$; after occlusion, the artery was released for the next $5.5 \mathrm{~h}$. Functional changes in vascularization during the I/R period were mapped through laser Doppler perfusion imaging, which is widely used for microcirculatory imaging in human and rodents; however, to the best of our knowledge, this is the first instance in which this technique has been used to monitor blood flow in a chick model. The flux intensity of the control and I/R groups was measured, and a significant difference observed in the blood flow of the two groups (Figure 1D). During ischemia, we observed a flux intensity drop of $>80 \%$ of the baseline normoxia level. The finding was consistent in all chick embryos employed; those with a lower drop $(<80 \%)$ were discarded. The flux intensity reached a normal value after reperfusion was allowed (Supplementary Figure S3). Furthermore, to validate the chick embryo I/R Hook model, we employed western blotting and biochemical assays.

\section{Western Blotting Analysis for I/R Injury}

Elevated expression of HIF $1 \alpha$ is considered a protective measure mediated by the cell to protect itself against I/R-inflicted damage (Bergeron et al., 1999; Lee, 2000; Baranova et al., 2007). Here, we measured HIFla expression, in the ischemic chick embryo model, as an early marker of ischemic tissue damage. We initially quantified HIF $1 \alpha$ expression after $2.5,5$, and $10 \mathrm{~min}$ of ischemia to the RVA. The result suggested that ischemia induced in the tissue even for such a short duration was sufficient to stabilize HIF1 $\alpha$ expression $\left({ }^{* * *} P<0.001\right.$; Figure 2A) in chick embryo. The observed fold changes during 2.5, 5, and $10 \mathrm{~min}$ of ischemia were 0.9-, 1.03-, and 1.14-fold, respectively. Although the fold changes during $10 \mathrm{~min}$ of ischemia were slightly higher (non-significant), the Kaplan-Meier survival curve showed 100\% viability within 5 min of treatment (Figure 2B). Thus, we applied $5 \mathrm{~min}$ of ischemia in subsequent experiments. Because the restoration of blood supply often causes more damage to the tissue than the ischemic episode itself, we analyzed the effect of reperfusion at different time intervals (Figure 2C): compared with control, the level of HIF-1 $\alpha$ expression increased rapidly after ischemia $\left({ }^{* *} P<0.001\right)$; however, no significant differences were observed between 0 and $24 \mathrm{~h}$ of reperfusion. Notably, no changes were observed in the reperfusion time window, and the 
A

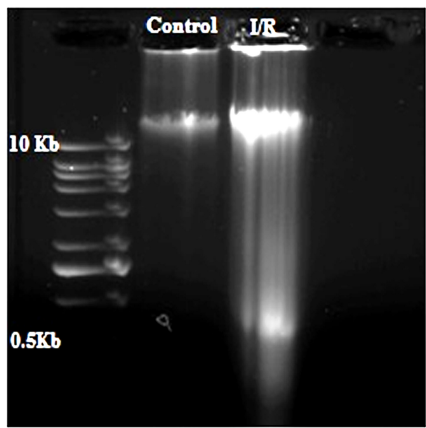

D

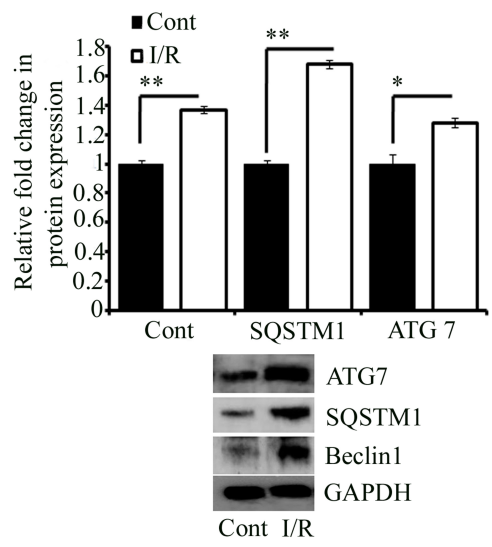

B

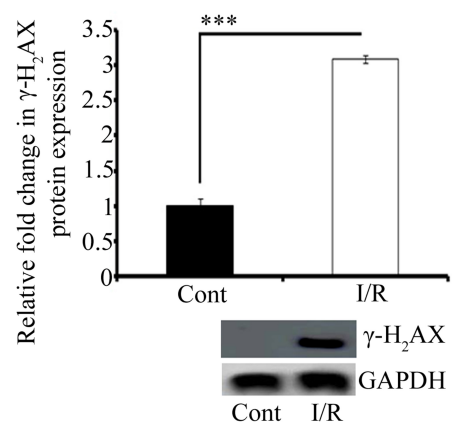

$\mathbf{E}$

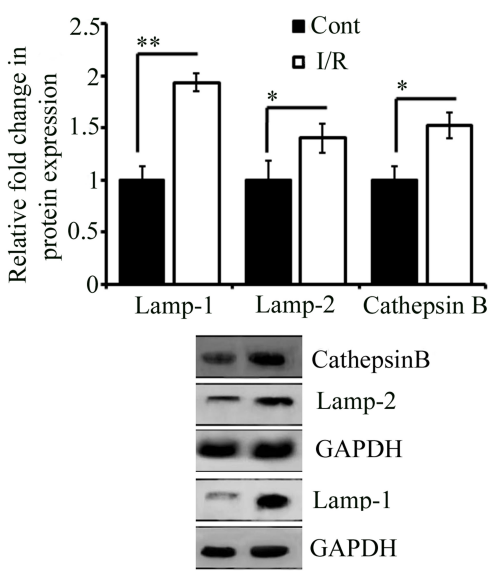

C

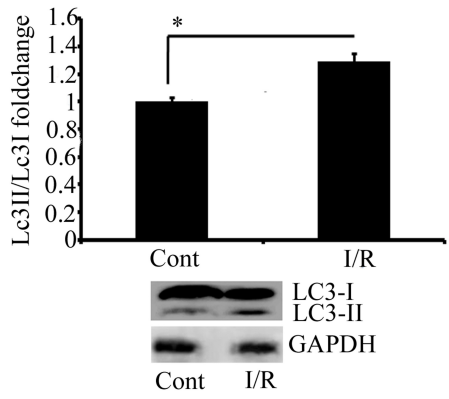

$\mathbf{F}$

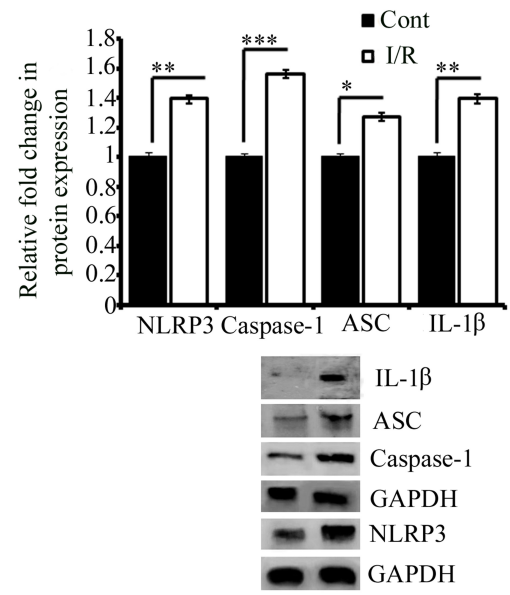

FIGURE 3 | Representative pictures of effect of I/R on DNA damage, cell survival, and inflammation. (A) DNA gel electrophoresis diagram. (B) The phosphorylation of $\mathrm{H} 2 \mathrm{AX}$ in response to I/R-induced DNA damage (***P $<0.001 \mathrm{vs}$. control). Western blot analysis expression level of LC3 I/II (*P < 0.05$)$ (C), Beclin1 $\left({ }^{* *} P<0.001\right)$, SQSTM1 $(* P<0.05)$, and ATG7 $(* * P<0.01)$ (D) and lysosomal associated proteins Lamp1 (** $\left.P<0.01\right)$, Lamp2 $(* P<0.05)$, and Cathepsin $\mathrm{B}\left({ }^{*} P<0.05\right)$ (E) in total protein extract from RVA of I/R treated vs. control group. (F) The expression of NLRP3 $(* * * P<0.001)$, Caspase-1 (** $\left.P<0.01\right)$, ASC (**P<0.01), and IL-1 $(* * P<0.01)$. Results represent mean $\pm \mathrm{SE}(n=3)$. The graph shows the densitometry quantification of western blot bands. Here control group represented Sham group. ${ }^{*} P<0.05,{ }^{* *} P<0.01$, and ${ }^{* * *} P<0.001$

maximum survival was obtained at $6 \mathrm{~h}$ (Figure 2D). Therefore, we used $6 \mathrm{~h}$ of reperfusion in subsequent experiments.

\section{Involvement of Oxidative Stress}

Ischemia-reperfusion activates several processes with detrimental effects on the tissue, including the generation of reactive oxygen species (ROS). Because NADPH oxidase 2 (NOX2) is a major source of $\mathrm{O}_{2}$ and $\mathrm{H}_{2} \mathrm{O}_{2}$, we investigated the contribution of NOX2 to oxidative stress in the chick embryo on the third day after $\mathrm{I} / \mathrm{R}$ by measuring the changes in NOX2 expression. Compared with control embryos, we obtained strong evidence that NOX2 augments the tissue injury by $61 \%$ in I/R embryos ( ${ }^{* *} P<0.01$; Figure $2 \mathrm{E}$ ). Moreover, we examined the expression of ORP-150, a novel stress protein that is activated in the pathophysiology of ischemic (Bando et al., 2004; Kitano et al., 2004) and oxidative (Goswami et al., 2003; Ozawa et al., 2005) diseases. Compared with the control group, ischemia, followed by reperfusion, upregulated ORP150 expression by approximately $76 \%$ in the I/R group
( ${ }^{* *} P<0.01$; Figure $\left.2 \mathrm{E}\right)$, which corroborated the aforementioned finding.

An important hallmark of $\mathrm{I} / \mathrm{R}$ injury is the detrimental and strong oxidative stress resulting from the intrinsic antioxidant body defense systems' response to ROS. Among the antioxidant defense systems, superoxide dismutases (SOD) are key antioxidant enzymes that provide the first line of defense against ROS by catalyzing the conversion of $\mathrm{O}_{2}$ to $\mathrm{H}_{2} \mathrm{O}_{2}$. Thus, we examined the activity of cytoplasmic and mitochondrial $\mathrm{SOD}$ in ischemic vessels. Compared with the control group, I/R enhanced the activity of cytoplasmic SOD1 by $80 \%\left({ }^{* *} P<0.01\right)$ and mitochondrial SOD2 by $112 \%\left({ }^{* *} P<0.01\right)$ in the $\mathrm{I} / \mathrm{R}$ group (Figure 2F). According to I/R research, the damage to the affected tissue results from the oxidative stress induced by free radicals, and the measurement of lipid peroxidation is one of the most commonly used assays for evaluating radical-induced damage (Svingen et al., 1979; Sevanian and Hochstein, 1985). We evaluated the level of lipid peroxides in the I/R and control groups. Our study confirmed the formation of thio-barbituric 
A
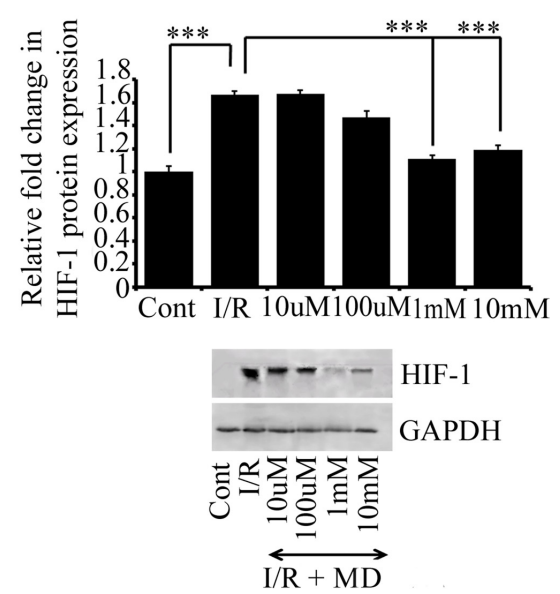

C
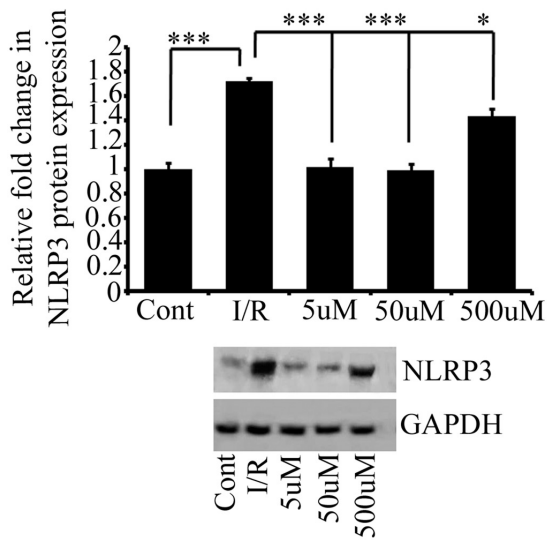

$\overleftrightarrow{\mathrm{I} / \mathrm{R}+\mathrm{MCC}-950}$
B
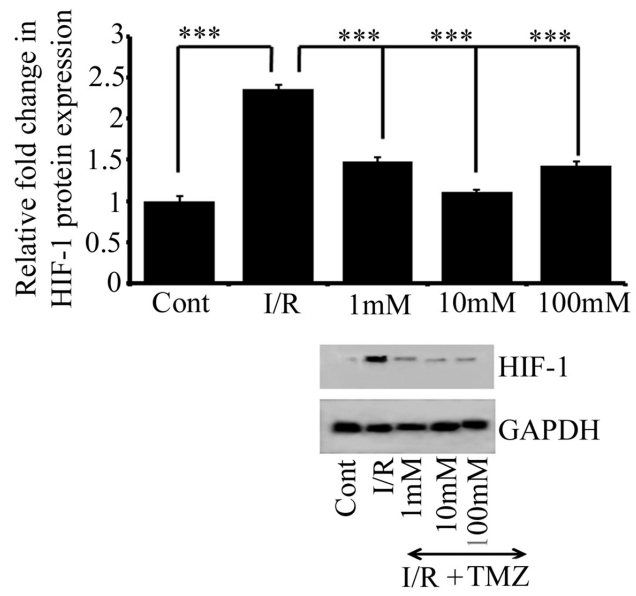

D

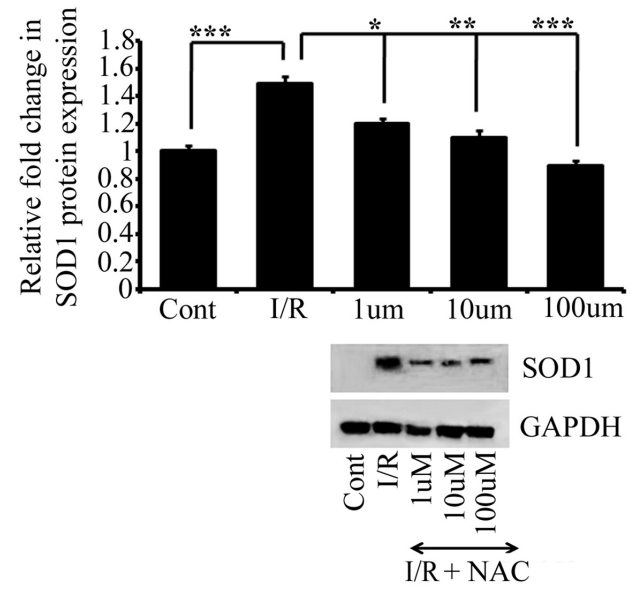

FIGURE 4 | The effect of drug treatments on I/R RVA. Western blot analysis for MD (A), TMZ (B), MCC950 (C), and NAC (D) shows that MD (1 mM, ***P < 0.001) and TMZ (1 mM, $\left.{ }^{* * *} P<0.001\right)$. Similarly, significant changes were found in the expression of MCC950 (5 $\left.\mu \mathrm{M},{ }^{* * *} P<0.001\right)$ and NAC (100 $\left.\mu \mathrm{M},{ }^{* * *} P<0.001\right)$ attenuates I/R mediated changes in I/R group compared to Ischemic group. Results represent mean \pm SE $(n=3)$. The graph shows the densitometry quantification of western blot bands. Control group represents Sham group. ${ }^{*} P<0.05,{ }^{* *} P<0.01$, and ${ }^{* * *} P<0.001$.

acid reactive species in ischemic RVA compared with nonischemic arteries ( ${ }^{* *} P<0.001$ vs. control; Figure 2G). We also estimated the nitric oxide (NO) level in I/R and control arteries using the Griess reagent, and the resulting pattern was the same as demonstrated in lipid peroxidation $\left({ }^{* * *} P<0.001\right.$ vs. control; Figure 2H).

\section{Model for DNA Integrity}

Reports have documented that I/R can cause DNA damage in cells and tissues (Ge et al., 2017; Kim, 2017; Hu et al., 2018). Thus, we examined the effect of $5 \mathrm{~min}$ of ischemia, followed by $5.5 \mathrm{~h}$ of reperfusion, on the mechanical integrity of DNA. Profound fragmentation of DNA was evident in the I/R group compared with the control group, indicating the loss of DNA integrity (Figure 3A). To confirm the results, we quantified the expression of H2AX, a highly sensitive marker of double-stranded DNA damage that localizes to the site of the DNA break. Western blot analysis of H2AX indicated that the I/R group showed two fold higher DNA damage than that in the control group $\left({ }^{* *} P<0.001\right.$; Figure 3B).

\section{Model for Cell Death Mechanisms}

Ischemia-reperfusion activates autophagy (Chen et al., 2017; Yang et al., 2017; Huang et al., 2018; Peng et al., 2018; Xie et al., 2018). Thus, we investigated the effect of $I / R$ on the autophagy mechanism in the chick embryo. As shown in Figures $4 \mathbf{A}, \mathbf{B}$, the expression of LC3 (autophagosome marker; ${ }^{*} P<0.05$ ), Beclin1 (a central regulator of autophagy in mammalian cells; ${ }^{* * *} P<0.001$ vs. control), p62 (cargo protein; ${ }^{*} P<0.05$ vs. control), and ATG7 (required for basal autophagy; ${ }^{* *} P<0.01$ vs. control) of the I/R group was significantly higher than that of the control group (Figures 3C,D). We next examined the expression of the following autolysosomal proteins: lysosomal-associated membrane proteins LAMP1 and LAMP2, and Cathepsin B. 
Their expression pattern showed a strong correlation with the expression of initiation and cargo proteins (Figure 3E). After $5 \mathrm{~min}$ of ischemia, followed by $5.5 \mathrm{~h}$ of reperfusion, the expression of LAMP1, LAMP2, and Cathepsin B increased by 94, 40, and $52 \%$ in $\mathrm{I} / \mathrm{R}$ arteries, respectively. We also tried to observe the effect of I/R on apoptosis (Supplementary Figure S4) and the outcome indicate that the model may also be used to study the other pathways of cell death (e.g., apoptosis).

\section{Chick Embryo as a Model for I/R Inflammation}

To verify the efficacy of this model for conducting inflammatory research, we evaluated the expression of the NOD-like receptor pyrin domain-containing protein 3 (NLRP3) inflammasome pathway, and pro-inflammatory cytokines $\mathrm{NF}-\mathrm{k} \beta$ and IFN $\gamma$, involved in exaggerating inflammation. This study provided evidence for the activation of both the NLRP3 inflammasome (Figure 3F) as well as NF-k $\beta$ and IFN $\gamma$ (Supplementary Figure S5) in response to I/R induced in the RVA. Six hours of I/R increased the expression of NLRP3, cleaved caspase-1, ASC, and cleaved IL-1 $\beta$ by 1.4-, 0.9-, 0.83-, and 1.3-fold, respectively, and the changes in the levels of NF-k $\beta$ and IFN $\gamma$ were 1.2-and 0.8 -fold, respectively.

\section{Treatment With Meldonium Dihydrate, Trimetazidine, MCC950, and N-Acetyl Cysteine}

The main advantage of generating a model is that it can be used to test the efficacy of drugs. To verify that the Hook I/R model can be used for drug screening, we evaluated the protective effect of meldonium dihydrate (MD), trimetazidine (TMZ), MCC950, and $N$-acetyl cysteine (NAC). Several doses of these drugs were tested; the doses were chosen arbitrarily (with 10-fold increases in the concentration of the primary dose), or the doses selected were intermediate between the dose selected for cell culture and that used in animal models in other studies. Six hours of I/R induced changes in the expression of HIF $1 \alpha$ and NLRP3 in the I/R group. However, compared with the I/R group, I/R induction was blocked in the drug-administered group treated with $\mathrm{MD}\left(1 \mathrm{mM},{ }^{* *} P<0.001\right.$; Figure 4A) and TMZ $(1 \mathrm{mM}$, ${ }^{* * *} P<0.001$; Figure 4B). Similarly, significant changes were found in the expression of MCC950 $\left(5 \mu \mathrm{M},{ }^{* * *} P<0.001\right.$; Figure 4C) and NAC $\left(100 \mu \mathrm{M},{ }^{* * *} P<0.001\right.$; Figure 4D) treated groups respectively, as compared to I/R group. The expression of the respective proteins in the I/R group and the groups treated with the MD, TMZ, MCC950, and NAC indicated that ischemia, inflammation and oxidative stress, respectively, were significantly ameliorated.

\section{DISCUSSION}

Ischemia-reperfusion research focuses on developing therapeutic strategies to prevent cell death and improve recovery. In this study, to overcome the existing challenges in $I / R$ research, we developed an I/R chick embryo model. We aimed to develop a reliable and reproducible model of $\mathrm{I} / \mathrm{R}$ to study stress signals (e.g., oxidative and inflammatory stress). In addition to the high output, simplicity, and flexibility of the model for routine analysis, the model can be used for short-term stem cell homing studies (ongoing studies).

Ischemia is the deprivation of blood supply; hence, tissues and the body parts are deprived of oxygen and nutrients (Hunt et al., 1985; Mansfield et al., 1997; Madarame et al., 2013; Matsubara et al., 2015), and ischemia is typically caused by the narrowing or blockage of blood vessels or arteries. Reperfusion is the only intervention that can reliably reduce the infarct size in animals and humans (Hale et al., 2013; Wei et al., 2016; Borges and Verdoorn, 2017; Misir et al., 2017; Sunagawa et al., 2018). Several preclinical cell culture and animal testing models are currently available to identify, assess, and prioritize the dayto-day new preventive and therapeutic inventions against I/R injury. However, each model has limitations; for example, cell culture models lack whole physiology, immune system, and microvasculature; similarly, rodents studies are highly regulated and supervised, costly, time-consuming, and have ethical issues. In the present study, we investigated, for the first time, the possibility of using chick embryos as a model organism to study I/R. Previous efforts have been made to develop a chick embryo-based flow-manipulation model for studies of shear stress (Hogers et al., 1999; Dittmar et al., 2006; Groenendijk et al., 2007; Wang et al., 2009). These studies have evaluated the consequences of low blood flow for embryo development and cardiovascular malformation. Recently, Majumder et al. (2010) used ligation to induce ischemia in a chick embryo; however, the model lacked the reperfusion phenomenon. Thus, in the present study, we developed a model that can efficiently recapitulate the I/R events. To validate the model, we employed laser Doppler perfusion imaging. The measuring capacity of Doppler imaging relies on the structure, density, and depth of the capillaries. In our study, the laser probe was directly adjusted onto the RVA, so that the flux intensity was measured with maximum accuracy. The Doppler reading showed a drop of $\geq 80 \%$ of the baseline during ischemia in the I/R group.

In chick embryos, vitelline vessels are responsible for the circulation of blood from embryos to the yolk sac. Through vitelline circulation, embryos obtain nutrients from the yolk and diffused oxygen from air; hence, blocking any of the vitelline vessels can interfere with nutrient and oxygen transport. Based on these facts, we induced ischemia by occluding the blood supply to the RVA for $5 \mathrm{~min}$, followed by reperfusion for another $5.5 \mathrm{~h}$. The present study clearly demonstrated that the occlusion of the RVA induced ischemia, as evident by laser Doppler imaging and HIF $1 \alpha$ expression. Oxidative and inflammatory stresses are among the pathophysiological changes postulated to occur in response to I/R (Aragno et al., 2003; Chen et al., 2007; Wong and Crack, 2008; Granger and Kvietys, 2015; Kurian et al., 2016; Rovcanin et al., 2016; Gao et al., 2017). Thus, we examined the expression of the following proteins involved in oxidative stress and inflammation: NOX2 (Lou et al., 2018; Zhang et al., 2018), ORP150 (Kitano et al., 2004; Ye et al., 2013), SOD1 (Jiang et al., 2015; Dibas et al., 2018), SOD2 (Haines et al., 2010; Xu et al., 2010), NLRP3 (He et al., 2017; Liu et al., 2018), NF-к $\beta$ (Su et al., 2017; Ye et al., 2017, 2018), and 
IFN $\gamma$ (Sun et al., 2016; Ferhat et al., 2018). The high expression of these proteins in the present $\mathrm{I} / \mathrm{R}$ model implied that even a short period of ischemia, followed by reperfusion, played a major role in exaggerating tissue damage. Furthermore, the induction of NF- $\mathrm{k} \beta$ and IFN $\gamma$ expression in the I/R embryo indicates that the present model can effectively be used to explore numerous inflammatory pathways involved in I/R.

Cells undergo cell death through many pathways, such as necrosis, apoptosis, and autophagy. Both apoptosis and autophagy are types of programmed cell death (PCD). Most knowledge on the role and regulation of PCD has been primarily obtained through three model systems: the nematode Caenorhabditis elegans, the fruit fly Drosophila melanogaster, and mouse (Fuchs and Steller, 2011). In this context, we tested the mechanism of cell survival and death in chick embryos. The expression of several proteins associated with autophagy was examined. The result suggested that $5 \mathrm{~min}$ of ischemia, followed by $5.5 \mathrm{~min}$ of reperfusion, promoted autophagy in chick arterial cells. The result indicated that a short period of $\mathrm{I} / \mathrm{R}$ was sufficient to activate autophagy. Furthermore, our result indicated that the present model can be used to study all events associated with autophagy, and may also be employed to study other PCD pathways (Supplementary Figure S4).

Although many notable drug development achievements have been made in the last two decades in ischemic research, a key challenge in drug candidate screening is the lack of a suitable screening model, which can translate preclinical drug candidates into clinical success (Andreadou et al., 2008; Bahjat et al., 2017). In this study, we critically evaluated the role anti-oxidative, antiischemic, and anti-inflammatory drugs after $6 \mathrm{~h}$ of $\mathrm{I} / \mathrm{R}$. The result indicated that treatment with the anti-ischemic drugs $\mathrm{MD}$ (Sisetskii et al., 1992; Hayashi et al., 2000) and TMZ (Zhou et al., 2012; Yao et al., 2015) reversed the I/R response in the arteries. MCC950, a potent and selective inhibitor of the NLRP3 inflammasome (Coll et al., 2015; Salla et al., 2018), also protected the RVA against $I / R$ in our model, corroborating the earlier reports of animal I/R models (Ye et al., 2017; Ismael et al., 2018). Additionally, we employed NAC, a scavenger of ROS, which was found to reverse the outcome of $6 \mathrm{~h}$ of I/R. Taken together, the results imply that the developed model can be effectively used to classify several drug types and their targets in $\mathrm{I} / \mathrm{R}$ research.

In addition to I/R research, the present model can be employed for a range of other pathological mechanisms associated with $\mathrm{I} / \mathrm{R}$ and for screening numerous drug types. Because of its high reproducibility, cost-effectiveness, and simplicity, we anticipate that our model can be a valuable resource for basic science and translational research, and that it can be widely used in $\mathrm{I} / \mathrm{R}$ research. A direct infarct measurement could also been a good indicator of $\mathrm{I} / \mathrm{R}$ mediated injury, and to map up the effect of various therapeutic drugs. Thus, we tried to quantify the infarct area, however, due to the delicate structure of the $72 \mathrm{~h}$ developed chicks we have yet not been able to measure the infarct area. Thus, further investigation is warranted for the comprehensive analysis of methods and pathways associated to I/R that we could not examine in this study.

\section{AUTHOR CONTRIBUTIONS}

SR contributed to experiment planning, conception, design, acquisition of data, analysis and interpretation of data, and drafting and revising manuscript critically. EF, AS, MAK, and PG contributed to acquisition of data. SR, TB, MK, and EF contributed to analysis and interpretation of data. $\mathrm{EF}$ and $\mathrm{TB}$ contributed to data preparation. AR provided the MCC950, reviewed the manuscript, and contributed to critical inputs to the experimentations.

\section{ACKNOWLEDGMENTS}

We are thankful to Dr. Jonaki Sen, Associate Professor, IIT Kanpur, India for her critical inputs, and providing us her laboratory facilities, and to SERB, Department of Science and Technology, Government of India for providing us Doppler Flow meter with the grant no. YSS/2015/001731.

\section{SUPPLEMENTARY MATERIAL}

The Supplementary Material for this article can be found online at: https://www.frontiersin.org/articles/10.3389/fphar. 2018.01034/full\#supplementary-material

FIGURE S1 | Represent the schematic picture of the third day chick embryo I/R experimentation. (A) The day 0 processing. At the day 0 , eggs were sterilized with $70 \%$ ethanol, and put into the $37^{\circ} \mathrm{C}$ egg incubator with $60-65 \%$ humidity. At day 1, the eggs were taken out for layering (B). (C) A normal white Leghorn egg just before I/R surgery. (D) A typical setup to induce I/R in the chick embryo. The probe of the Doppler flow meter was put onto the ischemic RVA ( $5 \pm 1 \mathrm{~mm}$ from the site of ischemia at distal end). (E) The magnified image of the setup: egg with micromanipulator and laser Doppler probe. (F) The insertion of the spinal need hook into the artery, and the lifting of the artery.

FIGURE S2 | A typical picture of the third day embryo; the rectangle shows the site of excision of the tissue for western blotting, The star represents the site of the occlusion, and the holes created on the right and left side of the RVA are represented by two circles on the right and left sides of the artery, and is to insert the needle beneath the artery to lift it up. (S2') The magnified image of S2. (S2") The area of excision of tissue in the vicinity of RVA. And the straight line represents the RVA emerging from the embryo trunk. The star on the line denotes the position of laser Doppler flow probe. The intersection represents the site of occlusion. From the site of occlusion the arteries were excised up to $15 \pm 1 \mathrm{~mm}$ (distal from the trunk), $5 \pm 1 \mathrm{~mm}$ each on the left and right side of the artery, and $2 \pm 1 \mathrm{~mm}$ toward the trunk. S2" is a representative of the right side of the chick embryo.

FIGURE S3 | A typical laser Doppler flow meter signal measured on 3-days-old embryo chick artery from a control group chick (A). (B) Events of baseline (1), immediate pre-lifting of RVA (2), during normoxia (3), immediate post-lifting of RVA (4), during ischemia (5), immediate pre-releasing of RVA (6), immediate post-reperfusion (7), during reperfusion (8) in ischemia treated group as recorded by laser Doppler flow meter.

FIGURE S4 | Western blot analysis expression level of Caspase-3 $(* * * P<0.01)$ in total protein extract from RVA of I/R treated vs. control group. Results represent mean $\pm \operatorname{SE}(n=3)$. The graph shows the densitometry quantification of western blot bands.

FIGURE S5 | Western blot analysis expression level of NF-k $\beta(* * * P<0.001)$ and IFN $\gamma\left({ }^{* * *} P<0.001\right)$ (Figure 4 C) in total protein extract from RVA of I/R treated vs. control group. Results represent mean \pm SE $(n=3)$. The graph shows the densitometry quantification of western blot bands. 


\section{REFERENCES}

Allen, D. D., Caviedes, R., Cardenas, A. M., Shimahara, T., Segura. Aguilar, J., and Caviedes P. A. (2005). Cell lines as in vitro models for drug screening and toxicity studies. Drug. Dev. Ind. Pharm. 31, 757-768. doi: 10.1080/ 03639040500216246

Andreadou, I., Iliodromitis, E. K., Koufaki, M., Farmakis, D., and Tsotinis, A., Kremastinos, D. (2008). Alternative pharmacological interventions that limit myocardial infarction. Curr. Med. Chem. 15, 3204-3213. doi: 10.2174/ 092986708786848550

Anvret, A., Ran, C., Westerlund, M., Gellhaar, S., Lindqvist, E., Pernold, K., et al. (2012). Adh1 and Adh1/4 knockout mice as possible rodent models for presymptomatic Parkinson's disease. Behav. Brain. Res. 227, 252-257. doi: 10.1016/ j.bbr.2011.10.040

Aragno, M., Cutrin, J. C., Mastrocola, R., Perrelli, M. G., Restivo, F., Poli, G., et al. (2003). Oxidative stress and kidney dysfunction due to ischemia/reperfusion in rat: attenuation by dehydro-epiandrosterone. Kid. Int. 64, 836-843. doi: 10.1046/j.1523-1755.2003.00152.x

Bahjat, F. R., Alexander, W. G., Kohama, S. G., Glynn, C., and Urbanski, H. F., Hobbs, T. R., et al. (2017). Preclinical development of a prophylactic neuroprotective therapy for the preventive treatment of anticipated ischemiareperfusion injury. Transl. Stroke Res. 8, 322-333. doi: 10.1007/s12975-0170532-8

Bando, Y., Tsukamoto, Y., Katayama, T., Ozawa, K., and Kitao, Y. (2004). ORP150/HSP12A protects renal tubular epithelium from ischemia-induced cell death. FASEB. J. 18, 1401-1403. doi: 10.1096/fj.03-1161fje

Baranova, O., Miranda, L. F., Pichiule, P., Dragatsis, I., Johnson, R. S., and Chavez, J. C. (2007). Neuron-specific inactivation of the hypoxia inducible factor 1alpha increases brain injury in a mouse model of transient focal cerebral ischemia. J. Neurosci. 27, 6320-6332. doi: 10.1523/JNEUROSCI.0449-07.2007

Bergeron, M., Yu, A. Y., Solway, K. E., Semenza, G. L., and Sharp, F. R. (1999). Induction of hypoxia-inducible factor-1 (HIF-1) and its target genes following focal ischaemia in rat brain. Eur. J. Neurosci. 11, 4159-4170. doi: 10.1046/j. 1460-9568.1999.00845.x

Borges, J. P., and Verdoorn, D. K. (2017). Cardiac ischemia/reperfusion injury: the beneficial effects of exercise. Adv. Exp. Med. Biol. 999, 155-179. doi: 10.1007/ 978-981-10-4307-9_10

Chen, C., Chen, W., Li, Y., Dong, Y., and Teng, X. Z. (2017). Hyperbaric oxygen protects against myocardial reperfusion injury via the inhibition of inflammation and the modulation of autophagy. Oncotarget. 8, 111522-111534. doi: 10.18632/oncotarget.22869

Chen, Q., Camara, A. K., Stowe, D. F., Hoppel, C. L., and Lesnefsky, E. J. (2007). Modulation of electron transport protects cardiac mitochondria and decreases myocardial injuryduring ischemia and reperfusion. Am. J. Physiol. Cell. Physiol. 292, C137-C147. doi: 10.1152/ajpcell.00270.2006

Coll, R. C., Robertson, A. A., Chae, J. J., Higgins, S. C., and Muñoz-Planillo, R., Inserra, M. C., et al., (2015). A small-molecule inhibitor of the NLRP3 inflammasome for the treatment of inflammatory diseases. Nat. Med. 21, 248-255. doi: 10.1038/nm.3806

Deryugina, E., and Quigley, J. (2009). Chick embryo chorioallantoic membrane model systems to study and visualize human tumor cell metastasis. Histochem. Cell. Biol. 130, 1119-1130. doi: 10.1007/s00418-008-0536-2

Dibas, A., Millar, C., Al-Farra, A., and Yorio, T. (2018). Neuroprotective effects of psalmotoxin-1, an acid-sensing ion channel (ASIC) inhibitor, in ischemia reperfusion in mouse eyes. Curr. Eye Res. 29, 1-13. doi: 10.1080/02713683.2018. 1454478

Dittmar, M. S., Vatankhah, B., Fehm, N. P., Schuierer, G., Bogdahn, U., Horn, M., et al. (2006). Fischer-344 rats are unsuitable for the MCAO filament model due to their cerebrovascular anatomy. J. Neurosci. Methods 156, 50-54. doi: 10.1016/j.jneumeth.2006.02.003

Ferhat, M., Robin, A., Giraud, S., Sena, S., Goujon, J. M., Touchard, G., et al. (2018). Contributes to kidney ischemia-reperfusion injury as an alarmin. J. Am. Soc. Nephrol. 29, 1272-1288. doi: 10.1681/ASN.2017060650

Fuchs, Y., and Steller, H. (2011). Programmed cell death in animal development and disease. Cell 147, 742-758. doi: 10.1016/j.cell.2011.10.033

Gao, X. J., Xie, G. N., Liu, L., Fu, Z. J., Zhang, Z. W., and Teng, L. Z. (2017). Sesamol attenuates oxidative stress, apoptosis and inflammation in focal cerebral ischemia/reperfusion injury. Exp. Ther. Med. 14, 841-847. doi: 10.3892/etm.2017.4550

Ge, M., Yao, W., Yuan, D., Zhou, S., Chen, X., Zhang, Y., et al. (2017). Brg-1 mediated Nrf2/HO-1 pathway activation alleviates hepatic ischemiareperfusion injury. Cell Death Dis. 8:e2841. doi: 10.1038/cddis.2017.236

Gonzalez, L. M., Moeser, A. J., and Blikslager, A. T. (2015). Animal models of ischemia-reperfusion-induced intestinal injury: progress and promise for translational research. Am. J. Physiol. Gastrointest. Liver Physiol. 308, G63-G75. doi: 10.1152/ajpgi.00112.2013

Goswami, S., Sheets, N. L., Zavadil, J., Chauhan, B. K., and Bottinger, E. P. (2003). Spectrum and range of oxidative stress responses of human lens epithelial cells to $\mathrm{H}_{2} \mathrm{O}_{2}$ insult. Invest. Ophthalmol. Vis. Sci. 44, 2084-2093. doi: 10.1167/iovs. 02-0882

Granger, D. N., and Kvietys, P. R. (2015). Reperfusion injury and reactive oxygen species: the evolution of a concept. Redox. Biol. 6, 524-551. doi: 10.1016/j.redox. 2015.08.020

Green, L. C., Wagner, D. A., Glogowski, K., Skipper, P. L., Wishnok, J. S., and Tannenbaum, S. R. (1982). Analysis of nitrate, nitrite and [15N] nitrate in biological fuids. Anal. Biochem. 126, 131-138. doi: 10.1016/0003-2697(82) 90118-X

Groenendijk, B. C., Van der Heiden, K., and Hierck, B. P. (2007). Poelmann, R.E. The role of shear stress on ET-1, KLF2, and NOS-3 expression in the developing cardiovascular system of chicken embryos in a venous ligation model. Physiology (Bethesda) 22, 380-389. doi: 10.1152/physiol.00023.2007

Haines, B. A., Mehta, S. L., Pratt, S. M., Warden, C. H., and Li, P. A. (2010). Deletion of mitochondrial uncoupling protein-2 increases ischemic brain damage after transient focal ischemia by altering gene expression patterns and enhancing inflammatory cytokines. J. Cereb. Blood. Flow Metab. 30, 1825-1833. doi: $10.1038 /$ jcbfm. 2010.52

Hale, S. L., Herring, M. J., and Kloner, R. A. (2013). Delayed treatment with hypothermia protects against the no-reflow phenomenon despite failure to reduce infarct size. J. Am. Heart. Assoc. 2:e004234. doi: 10.1161/JAHA.112. 004234

Harvey, W. (1628). Exercitatio Anatomica de Motucordisetsanguinis in Animalibus. Springfield, MO: The Springfield publishing company. 43. doi: 10.1016/S00028703(28)90110-6

Hayashi, Y., Tajima, K., Kirimoto, T., Miyake, H., and Matsuura, N. (2000). Cardioprotective effects of MET-88, a gamma-butyrobetaine hydroxylase inhibitor, on cardiac dysfunction induced by ischemia/reperfusion in isolated rat hearts. Pharmacology 61, 238-243. doi: 10.1159/00002 8407

He, Q., Li, Z., Wang, Y., Hou, Y., and Li, L. (2017). Resveratrol alleviates cerebral ischemia/reperfusion injury in rats by inhibiting NLRP3 inflammasome activation through Sirtl-dependent autophagy induction. Int. Immunopharmacol. 50, 208-215. doi: 10.1016/j.intimp.2017.06.029

Hogers, B., DeRuiter, M. C., Gittenberger-de Groot, A. C., and Poelmann, R. E. (1999). Extraembryonic venous obstructions lead to cardiovascular malformations and can be embryo lethal. Cardiovasc. Res. 41, 87-99. doi: 10.1016/S0008-6363(98)00218-1

Horvath, P., Aulner, N., Bickle, M., Anthony, M., and Nery, D, E. (2016). Screening out irrelevant cell-based models of disease. Nat. Rev. Drug. Discov. 15, 751-769. doi: $10.1038 / \mathrm{nrd} .2016 .175$

Hu, Q., Ren, J., Li, G., Wu, J., Wu, X., Wang, G., et al. (2018). The mitochondrially targeted antioxidant MitoQ protects the intestinal barrier by ameliorating mitochondrial DNA damage via the Nrf2/ARE signaling pathway. Cell Death Dis. 9:403. doi: 10.1038/s41419-018-0436-x

Huang, K. Y., Liang, S., Yu, M. L., Fu, S. P., Chen, X., and Lu, S. F. (2016). A systematic review and meta-analysis of acupuncture for improving learning and memory ability in animals. BMC Complement. Altern. Med. 16:297. doi: 10.1186/s12906-016-1298-3

Huang, X., Wu, H., Jiang, R., Sun, G., and Shen, J. et al. (2018). The antidepressant effects of $\alpha$-tocopherol are related to activation of autophagy via the AMPK/mTOR pathway. Eur. J.Pharmacol. 883, 1-7. doi: 10.1016/j.ejphar. 2018.05.020

Hunt, J. E., Walton, L. A., and Ferguson, R. A. (1985). Brachial artery modifications to blood flow-restricted handgrip training and detraining. J. Appl. Physiol. 112, 956-961. doi: 10.1152/japplphysiol.00905 
Ismael, S., Zhao, L., Nasoohi, S., and Ishrat, T. (2018). Inhibition of the NLRP3inflammasome as a potential approach for neuroprotection after stroke. Sci. Rep. 13:5971. doi: 10.1038/s41598-018-24350-x

Jiang, Y., Brynskikh, A. M., S-Manickam, D., and Kabanov, A. V. (2015). SOD1 nanozyme salvages ischemic brain by locally protecting cerebral vasculature. J. Control Release 213, 36-44. doi: 10.1016/j.jconrel.2015.06.021

Kalogeris, T., Baines, C. P., Krenz, M., and Korthuis, R. J. (2012). Cell biology of ischemia/reperfusion injury. Int. Rev. Cell. Mol. Biol. 298, 229-317. doi: 10.1016/B978-0-12-394309-5.00006-7

Kalogeris, T., Baines, C. P., Krenz, M., and Korthuis, R. J. (2016). Ischemia/reperfusion. Compr. Physiol. 7, 113-170. doi: 10.1002/cphy.c160006

Kim, J. (2017). Spermidine is protective against kidney ischemia and reperfusion injury through inhibiting DNA nitration and PARP1 activation. Anat. Cell. Biol. 50, 200-206. doi: 10.5115/acb.2017.50.3.200

Kitano, H., Nishimura, H., Tachibana, H., Yoshikawa, H., and Matsuyama. T. (2004). ORP150 ameliorates ischemia/reperfusion injury from middle cerebral artery occlusion in mouse brain. Brain Res. 1015, 122-128. doi: 10.1016/j. brainres.2004.04.058

Kurian, G. A., Rajagopal, R., Vedantham, S., and Rajesh, M. (2016). The role of oxidative stress in myocardial ischemia and reperfusion injury and remodeling: revisited. Oxid. Med. Cell. Longev. 2016:1656450. doi: 10.1155/2016/1656450

Lai, I. R., Chang, K. J., Chen, C. F., and Tsai, H. W. (2006). Transient limb ischemia induces remote preconditioning in liver among rats: the protective role of heme oxygenase-1. Transplantation 81, 1311-1317. doi: 10.1097/01.tp.0000203555. 14546.63

Lee, S. H. (2000). Early expression of angiogenesis factors in acute myocardial ischemia and infarction. N. Engl. J. Med. 342, 626-633. doi: 10.1056/ NEJM200003023420904

Lee, S. J., Yeom, E., Ha, H., and Nam, K. H. (2011). Cardiac outflow and wall motion in hypothermic chick embryos. Microvasc. Res. 82, 296-303. doi: 10.1016/j.mvr. 2011.09.005

Linfante, I., and Cipolla, M. J. (2016). Improving reperfusion therapies in the era of mechanical thrombectomy. Transl. Stroke Res. 7, 294-302. doi: 10.1007/s12975016-0469-3

Liu, Z., Qu, M., Yu, L., Song, P., and Chang, Y. (2018). Artesunate inhibits renal ischemia-reperfusion-mediated remote lung inflammation through attenuating ROS-induced activation of NLRP3 inflammasome. Inflammation 41, 1546-1556. doi: 10.1007/s10753-018-0801-z

Lou, Z., Wang, A. P., Duan, X. M., Hu, G. H., and Song, G. L. (2018). Upregulation of NOX2 and NOX4 Mediated by TGF- $\beta$ signaling pathway exacerbates cerebral ischemia/reperfusion oxidative stress injury. Cell Physiol. Biochem. 46, 2103-2113. doi: 10.1159/000489450

Madarame, H., Kurano, M., Fukumura, K., Fukuda, T., and Nakajima, T. (2013). Haemostatic and inflammatory responses to blood flow-restricted exercise in patients with ischaemic heart disease: a pilot study. Clin. Physiol. Funct. Imaging 33, 11-17. doi: 10.1111/j.1475-097X.2012.01158.x

Majumder, S., Ilayaraja, M., Seerapu, H. R., Sinha, S., Siamwala, J. H., et al. (2010). Chick embryo partial ischemia model: a new approach to study ischemia ex vivo. PLoS. One. 5:e10524. doi: 10.1371/journal.pone.0010524

Mansfield, J. R, Sowa, M. G., Scarth, G. B., Somorjai, R. L., and Mantsch, H. H. (1997). Fuzzy C means clustering and principal component analysis of time series from near-infrared imaging of forearm ischemia. Comput. Med. Imaging Graph. 21, 299-308. doi: 10.1016/S0895-6111(97)00018-9

Mathes, D., Weirather, J., Nordbeck, P., Arias-Loza, A. P., and Burkard, M. (2016). $\mathrm{CD} 4{ }^{+}$Foxp3 + T-cells contribute to myocardial ischemia-reperfusion injury. J. Mol. Cell. Cardiol. 101, 99-105. doi: 10.1016/j.yjmcc.2016.10.007

Matsubara, Y., Matsumoto, T., Inoue, K., Matsuda, D., and Yoshiga, R. (2015). Sarcopenia is a risk factor for cardiovascular events experienced by patients with critical limb ischemia. J. Vasc. Surg. 65, 1390-1397. doi: 10.1016/j.jvs.2016. 09.030

McBride, D. W., and Zhang, J. H. (2017). Precision stroke animal models: the permanent MCAO Model should be the primary model, not transient MCAO. Transl. Stroke. Res. 8, 397-404. doi: 10.1007/s12975-017-0554-2

Milcan, A., Arslan, E., Bagdatoglu, O. T., Bagdatoglu, C., Polat, G., Kanik, A., et al. (2004). The effect of alprostadil on ischemia-reperfusion injury of peripheral nerve in rats. Pharmacol. Res. 49, 67-72. doi: 10.1016/j.phrs.2003.07.008

Misir, M., Renić, M., Novak, S., Mihalj, M., Ćosić, A., Vesel, M., et al. (2017). Hyperbaric oxygenation and 20-hydroxyeicosatetreanoic acid inhibition reduce stroke volume in female diabetic sprague-dawley rats. Exp. Physiol. 102, 1596-1606. doi: 10.1113/EP086402

Ozawa, K., Miyazaki, M., Matsuhisa, M., Takano, K., and Nakatani, Y., (2005). The endoplasmic reticulum chaperone improves insulin resistance in type 2 diabetes. Diabetes Metab. Res. Rev. 54, 657-663. doi: 10.2337/diabetes.54.3.657

Peng, C., Rao, W., Zhang, L., Gao, F., and Hui, H. (2018). Mitofusin 2 exerts a protective role in ischemia reperfusion injury through increasing autophagy. Cell. Physiol. Biochem. 46, 2311-2324. doi: 10.1159/000489621

Ross, J. L., Queme, L. F., Cohen, E. R., Green, K. J., Lu, P., Shank, T. K., et al. (2016). Muscle IL1 $\beta$ drives ischemic myalgia via ASIC3-mediated sensory neuron sensitization. J. Neurosci. 36, 6857-6871. doi: 10.1159/000489621

Rovcanin, B., Medic, B., Kocic, G., Cebovic, T., and Ristic, M. (2016). Molecular dissection of renal ischemiareperfusion: oxidative stress and cellular events. Curr. Med. Chem. 23, 1965-1980. doi: 10.2174/0929867323666160112122858

Salla, M., Butler, M. S., Massey, N. L., Reid, J. C., Cooper, M. A., and Robertson, A. A. B. (2018). Synthesis of deuterium-labelled analogues of NLRP3 inflammasome inhibitor MCC950. Bioorg. Med. Chem. Lett. 28, 793-795. doi: 10.1016/j.bmcl.2017.12.054

Schmeer, C., Gámez, A., Tausch, S., Witte, O. W., and Isenmann, S. (2008). Statins modulate heat shock protein expression and enhance retinal ganglion cell survival after transient retinal ischemia/reperfusion in vivo. Invest. Ophthalmol. Vis. Sci. 49, 4971-4978. doi: 10.1167/iovs.07-1597

Seabra, R., and Bhogal, N. (2010). In vivo research using early life stage models. In Vivo 24, 457-62.

Sevanian, A., and Hochstein, P. (1985). Mechanisms and consequences of lipid peroxidation in biological systems. Annu. Rev. Nutr. 5, 365-390. doi: 10.1146/ annurev.nu.05.070185.002053

Silachev, D. N., Usatikova, E. A., Pevzner, I. B., Zorova, L. D., Babenko, V. A., Gulyaev, M. V., et al. (2017). Effect of anesthetics on efficiency of remote ischemic preconditioning. Biochemistry (Mosc). 82, 1006-1016. doi: 10.1134/ S0006297917090036

Sisetskii, A. P., Artiukh, V. P., Sakharchuk, I. I., and Starodub, N. F. (1992). The characteristics of the action of mildronate (dihydrate 3-(2,2,2trimethylhydrazine)propionate) on the red blood parameters in heart failure. Eksp. Klin. Farmakol. 55, 20-21.

Smith, A. F., Nitzsche, B., Maibier, M., Pries, A. R., and Secomb, T. W. (2016). Microvascular hemodynamics in the chick chorioallantoic membrane. Microcirculation 23, 512-522. doi: 10.1111/micc.12301

Sommer, C. J. (2017). Ischemic stroke: experimental models and reality. Acta Neuropathol. 133, 245-261. doi: 10.1007/s00401-017-1667-0

Strand-Amundsen, R. J., Reims, H. M., Reinholt, F. P., Ruud, T. E., and Yang, R. (2018). Ischemia/reperfusion injury in porcine intestine - Viability assessment. World J. Gastroenterol. 24, 2009-2023. doi: 10.3748/wjg.v24.i18.2009

Su, D., Cheng, Y., Li, S., Dai, D., and Zhang, W. (2017). Sphk1 mediates neuroinflammation and neuronal injury via TRAF2/NF- $\kappa \mathrm{B}$ pathways in activated microglia in cerebral ischemia reperfusion. J. Neuroimmunol. 15, 35-41. doi: 10.1016/j.jneuroim.2017.01.015

Sun, P., Liu, J., Li, W., Xu, X., Gu, X., Li, H. Y., et al. (2016). Human endometrial regenerative cells attenuate renal ischemia reperfusion injury in mice. J. Transl. Med. 28, 14-28. doi: 10.1186/s12967-016-0782-3

Sunagawa, G., Saku, K., Arimura, T., Nishikawa, T., and Mannoji, H. (2018). Mechano-chronotropic unloading during the acute phase of myocardial infarction markedly reduces infarct size via the suppression of myocardial oxygen consumption. J. Cardiovasc. Transl. Res. doi: 10.1007/s12265-018-9809$\mathrm{x}$ [Epub ahead of print].

Svingen, B. A., Buege, J. A., O'Neal, F. O., and Aust, S. D. (1979). The mechanism of NADPH-dependent lipid peroxidation. The propagation of lipid peroxidation. J. Biol. Chem. 254, 5892-5899.

Tejada, T., Tan, L., Torres, R. A., Calvert, J. W., and Lambert, J. P. (2016). IGF1 degradation by mouse mast cell protease 4 promotes cell death and adverse cardiac remodeling days after a myocardial infarction. Proc. Natl. Acad. Sci. U.S.A. 21, 6949-6954. doi: 10.1073/pnas.1603127113

Utley, H. G., Bernheim, F., and Hochsein, P. (1967). Effect of sulfhydryl reagents on peroxidation of microsomes. Arch. Biochem. Biophys. 118, 29-32. doi: 10.1016/0003-9861(67)90273-1

Wang, Y., Dur, O., Patrick, M. J., Tinney, J. P., Tobita, K., Keller, B, B., et al. (2009). Aortic arch morphogenesis and flow modelling in the chick embryo. Ann. Biomed. Eng. 37, 1069-1081. doi: 10.1007/s10439-009-9682-5 
Wei, Y., Xu, M., Ren, Y., Lu, G., and Xu, Y., (2016). The cardioprotection of dihydrotanshinone I against myocardial ischemia-reperfusion injury via inhibition of arachidonic acid $\omega$-hydroxylase. Can. J. Physiol. Pharmacol. 94, 1267-1275. doi: 10.1139/cjpp-2016-0036

Wilson, S., and Chambers, A. (2004). Experimental metastasis assays in the chick embryo. Curr. Protoc. Cell. Biol. 19:19.6. doi: 10.1002/0471143030.cb1906s21

Wong, C. H., and Crack, P. J. (2008). Modulation of neuro-inflammation and vascular response by oxidative stress following cerebral ischemia-reperfusion injury. Curr. Med. Chem. 15, 1-14. doi: 10.2174/092986708783330665

Xie, Y., Jiang, D., Xiao, J., Fu, C., Zhang, Z., Ye, Z., et al. (2018). Ischemic preconditioning attenuates ischemia/reperfusion-induced kidney injury by activating autophagy via the SGK1 signaling pathway. Cell Death Dis. 9:338. doi: 10.1038/s41419-018-0358-7

Xiong, W., Wu, Y., Xian, W., Song, L., and Hu, L. (2018). DAPK1-ERK signal mediates oxygen glucose deprivation reperfusion induced apoptosis in mouse N2a cells. J. Neurol. Sci. 15, 210-219. doi: 10.1016/j.jns.2018.01.003

Xu, L., Emery, J. F., Ouyang, Y. B., Voloboueva, L. A., and Giffard, R. G. (2010). Astrocyte targeted overexpression of Hsp72 or SOD2 reduces neuronal vulnerability to forebrain ischemia. Glia 58, 1042-1049. doi: 10.1002/glia.20985

$\mathrm{Xu}$, Z., Alloush, J., Beck, E., and Weisleder, N. (2014). A murine model of myocardial ischemia-reperfusion injury through ligation of the left anterior descending artery. J. Vis. Exp. 86:51329. doi: 10.3791/51329

Yan, L. L., Zhang, W. Y., Wei, X. H., Yan, L., and Pan, C. S. (2018). Gualou xiebai decoction, a traditional chinese medicine, prevents cardiac reperfusion injury of hyperlipidemia rat via energy modulation. Front. Physiol. 4:296. doi: 10.3389/fphys.2018.00296

Yang, W., Chen, J., Meng, Y., Chen, Z., and Yang, J. (2018). Novel targets for treating ischemia-reperfusion injury in the liver. Int. J. Mol. Sci. 19:E1302. doi: 10.3390/ijms19051302

Yang, Y., Chen, S., Zhang, Y., Lin, X., and Song, Y. (2017). Induction of autophagy by spermidine is neuroprotective via inhibition of caspase 3-mediated Beclin 1 cleavage. Cell Death Dis. 8:e2738. doi: 10.1038/cddis.2017.161

Yao, X., Li, Y., Tao, M., Wang, S., and Zhang, L. (2015). Effects of glucose concentration on propofolcardioprotection against myocardial ischemia reperfusion injury in isolated rat hearts. J. Diabetes Res. 2015:592028. doi: $10.1155 / 2015 / 592028$

Ye, X., Shen, T., Hu, J., Zhang, L., Zhang, Y., Bao, L., et al. (2017). Purinergic $2 \mathrm{X} 7$ receptor/NLRP3 pathway triggers neuronal apoptosis after ischemic stroke in the mouse. Exp. Neurol. 292, 46-55. doi: 10.1016/j.expneurol.2017. 03.002

Ye, Y., Shan, Y., Bao, C., Hu, Y., and Wang, L. (2018). Ginsenoside Rg1 protects against hind-limb ischemia reperfusion induced lung injury via NF- $\mathrm{B} / \mathrm{COX}-2$ signaling pathway. Int. Immunopharmacol. 60, 96-103. doi: 10.1016/j.intimp. 2018.04.040

Ye, Z., Wang, N., Xia, P., Wang, E., Liao, J., and Guo, Q. (2013). Parecoxib suppresses CHOP and Foxol nuclear translocation, but increases GRP78 levels in a rat model of focal ischemia. Neurochem. Res. 38, 686-693. doi: 10.1007/ s11064-012-0953-4

Zhang, L., Wang, X., Wu, Y., Lu, X., and Chidiac, P. (2018). Maternal diabetes up-regulates NOX2 and enhances myocardial ischaemia/reperfusion injury in adult offspring. J. Cell. Mol. Med. 22, 2200-2209. doi: 10.1111/jcmm. 13500

Zhou, Y., Gong, G., Yang, W., Wang, Y., and Xu, J. (2012). The cardioprotective effect of TG-6, a newly synthesized compound, on ischemia-reperfusion injury in rats. Eur. J. Pharmacol. 683, 190-196. doi: 10.1016/j.ejphar.2012. 01.047

Conflict of Interest Statement: The authors declare that the research was conducted in the absence of any commercial or financial relationships that could be construed as a potential conflict of interest.

Copyright (c) 2018 Fauzia, Barbhuyan, Shrivastava, Kumar, Garg, Khan, Robertson and Raza. This is an open-access article distributed under the terms of the Creative Commons Attribution License (CC BY). The use, distribution or reproduction in other forums is permitted, provided the original author(s) and the copyright owner(s) are credited and that the original publication in this journal is cited, in accordance with accepted academic practice. No use, distribution or reproduction is permitted which does not comply with these terms. 